\title{
Heat Transfer Between Concrete Bored Cast-In-Place Piles and Surrounding Frozen Soil in Ice-Rich Area
}

\author{
Ning Yan, Tianlai Yu* \\ College of Civil Engineering, Northeast Forestry University, Harbin, China \\ Email address: \\ yn19940610@126.com (Ning Yan), zyz23869@163.com (Tianlai Yu) \\ ${ }^{*}$ Corresponding author
}

\section{To cite this article:}

Ning Yan, Tianlai Yu. Heat Transfer Between Concrete Bored Cast-In-Place Piles and Surrounding Frozen Soil in Ice-Rich Area. Journal of Civil, Construction and Environmental Engineering. Vol. 5, No. 5, 2020, pp. 102-107. doi: 10.11648/j.jccee.20200505.11

Received: August 10, 2020; Accepted: August 28, 2020; Published: September 19, 2020

\begin{abstract}
Based on the concrete test of foundation pile and the heat transfer theory between pile and soil, the heat transfer rule of pile and soil in ice-rich tundra is studied. The results show that the heat flow of foundation pile can be divided into vertical and horizontal heat flows. The vertical heat flow mainly occurs at the top of the pile and reaches the maximum value of $15.36 \mathrm{w} / \mathrm{m} 2$ on $3 \mathrm{~d}$. It caused the pile top temperature to drop so fast that it dropped below $0^{\circ} \mathrm{C}$ in $3 \mathrm{~d}$. The value of the horizontal heat flow is 2 3 times that of the vertical heat flow. Its distribution is in descending order: the middle, the top and the bottom of the pile. The maximum temperature difference between pile center and pile wall is $6.8^{\circ} \mathrm{C}$ because of transverse heat flow. Local high temperature zone is formed inside the pile due to the relatively slow absorption process of thawing permafrost. Then the temperature dropped rapidly, reaching $0^{\circ} \mathrm{C}$ at $28 \mathrm{~d}$. The maximum disturbance radius in the frozen soil reaches $1.5 \mathrm{~m}$. Insulation layer can be added to the outside of the foundation pile during construction to obtain more uniform concrete temperature field, so as to improve the concrete strength and reduce the disturbance to the frozen soil. The construction period should be in summer.
\end{abstract}

Keywords: Ice-Rich Permafrost, Temperature Field, Vertical and Horizontal Heat Flows, Cast-In-Place Concrete Pile

\section{Introduction}

With the global climate warms, permafrost has gradually become degraded patchy permafrost in The Greater Khingan Mountains region of China [1]. The area is mostly ice-rich permafrost. Permafrost is a multiphase complex system composed of soil particles, ice, unfrozen water and gas. The influence of permafrost on engineering practice is mainly caused by the different combinations of these complex phases $[2,3]$.

Bored cast-in-place pile is the preferred foundation type of bridge engineering in permafrost area [4, 5], it has the advantages of mature design theory and construction technology and strong applicability. Therefore, 90\% of the bridge foundation adopts cast-in-place [6,7]. Domestic and foreign scholar have done a lot of research on permafrost. Domestic scholar Xiong Wei created the governing equation of temperature field of pile foundation in permafrost region [8]. Shang Yunhu analyzed the influence of pile foundation on ground temperature of permafrost [9]. Wang $\mathrm{Xu}$ analyzed the pile foundation under different permafrost conditions and compared the corresponding freezing time [10, 11]. Foreign scholar Dong-Gen $\mathrm{C}$ adjusted different inlet temperature and hydration heat, and analyzed the temperature change rule of permafrost [13]. Lei Shen finds that cracking of mass concrete structures is inevitable [14]. Orlando B. Andersland and B Ladanyi found the potential problem of new concrete freezing during the construction of cast-in-place concrete piles [15].

To sum up, previous researches on pile and soil structure mainly focus on pile foundation quality, permafrost disturbance and freezing problems, and finite element model simulation analysis. The study of heat transfer between pile and soil under harsh geological conditions has not been reported. Therefore, based on the concrete test of foundation pile and the heat transfer theory between pile and soil, the heat transfer rule of pile and soil in ice-rich tundra is studied. The conclusion can be used as a reference for the project construction in this area. 


\section{Project Profile}

Based on jingmo highway bridge concrete bored cast-in-place piles project research. The test site is located in the patchy permafrost area with low hills in Mohe County, The Greater Khingan Mountains, Heilongjiang Province, China. East longitude $121^{\circ} 07^{\prime} \sim 124^{\circ} 20^{\prime}$, North latitude $52^{\circ} 10^{\prime} \sim 53^{\circ} 33^{\prime}$, Average altitude is $550 \mathrm{~m}$ [16], The average annual glacial period is 7 months [17], The maximum freezing depth in this area is $2.5 \mathrm{~m} \sim 3.0 \mathrm{~m}$. The site is located near Pile 11 of The K424+380 Permafrost Bridge. The diameter of pile foundation is $1.4 \mathrm{~m}$ and the pile length is $11.5 \mathrm{~m}$.

\subsection{Temperature Field Monitoring Scheme}

Eight temperature measuring holes, numbered $\mathrm{A} \sim \mathrm{H}$, were set in the base pile and its periphery respectively. See Figure 1 (a). Fourteen measuring points is arranged along the depth of each temperature measuring hole. The boundary of soil layer should be considered at the measuring points, and the distance between the sensors is $20-130 \mathrm{~cm}$. As shown in Figure 1 (b).

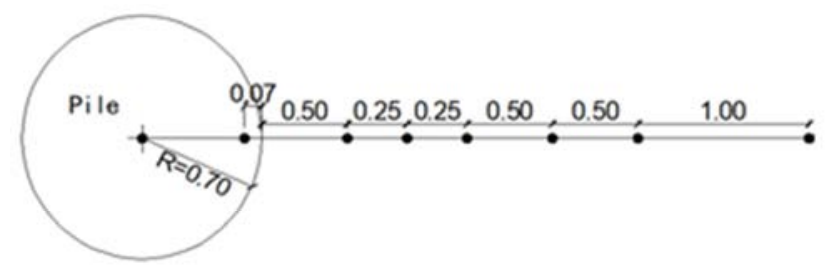

(a) horizontal (m)

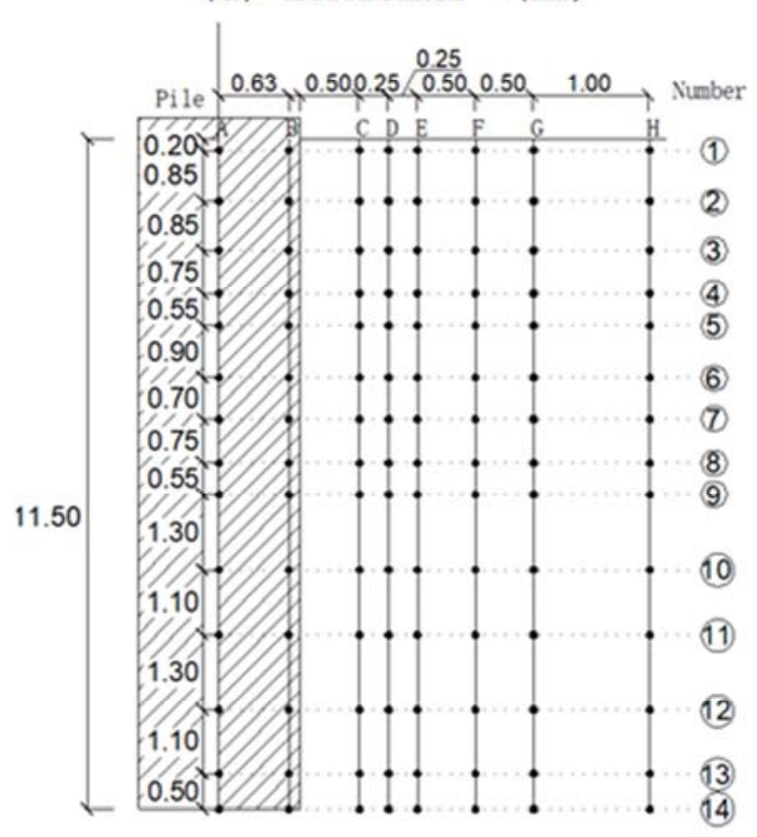

(b) vertical (m)

Figure 1. Arrangement of temperature measuring points.

The sensor is a resistance type temperature sensing element $\mathrm{DS} 18 \mathrm{~B} 2$. The temperature collection range is $-55 \sim+125^{\circ} \mathrm{C}$, and the accuracy is $\pm 0.2^{\circ} \mathrm{C}$. Jmwt-64rt system is used for automatic collection. The system is powered by batteries in winter and solar energy in summer. The temperature of concrete is tested once before pouring. Temperature data were collected every 4 hours after concrete was poured until 24 hours. After, temperature data will be collected once a day.

\subsection{Geological Conditions}

When the temperature measuring hole is laid, the permafrost in the temperature measuring hole is taken and stored at low temperature. See the specification for frozen soil sampling method [18]. See Figures 2 and 3.

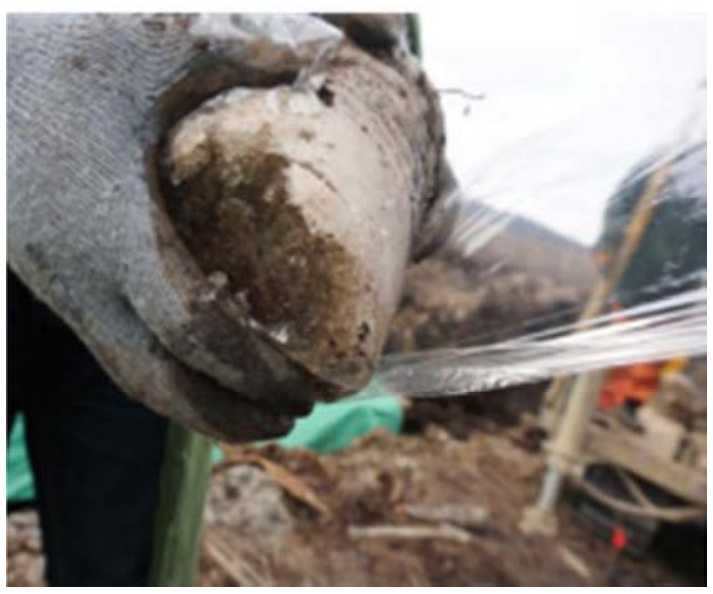

Figure 2. Collecting soil samples.

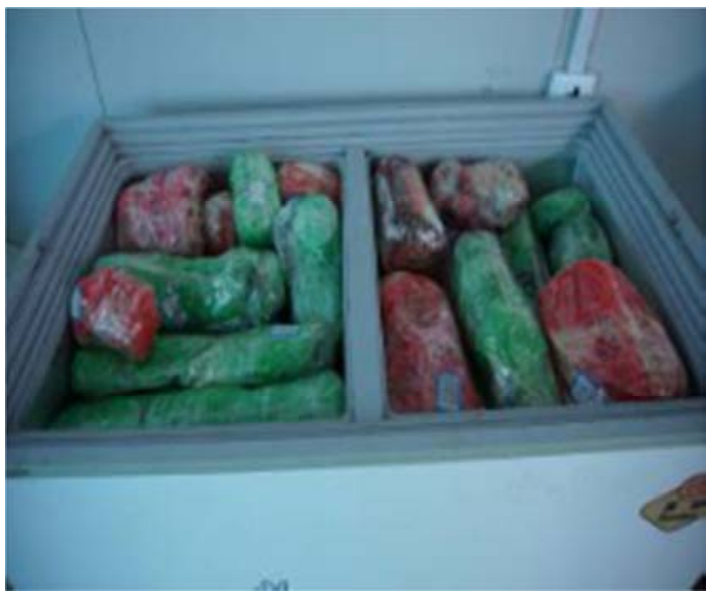

Figure 3. Keep soil samples in low temperature.

According to the soil samples, the types of soil are determined, and the names of each soil layer are defined respectively by referring to the provisions in Appendix B of the specification on the naming of ice-bearing characteristics of frozen soil [18]. See Tables 1 and 2.

In Table 2, there are six soil layers in permafrost around the pile. The temperature field at depths of $0.20 \mathrm{~m}, 1.05 \mathrm{~m}, 2.65 \mathrm{~m}$, $4.10 \mathrm{~m}, 5.55 \mathrm{~m}, 7.40 \mathrm{~m}, 9.80 \mathrm{~m}$ and $11.50 \mathrm{~m}$ was studied by taking the top of the pile, bottom of the pile and the center point of each soil layer.

\section{Change rule of Pile-Soil Temperature}

For cast-in-place concrete pile, the concrete hydration 
reaction should give off $50 \%$ heat from 0 to 3 days, and reach $75 \%$ on 7 days, and then gradually reduce. In order to better study the hydration heat of pile, its influence on the temperature of foundation pile and surrounding permafrost. In this paper, the temperature field within 28 days after concrete pouring is analyzed.

Table 1. Try of permafrost.

\begin{tabular}{|c|c|c|c|}
\hline Name & Characteristics of ice & & try of permafrost \\
\hline permafrost & Frozen soil with visible ice but with a thickness of less than $25 \mathrm{~mm}$ & $\begin{array}{l}\text { Permafrost with an ice film around the particles } \\
\text { Irregularly striding bands of ice permafrost }\end{array}$ & $\begin{array}{l}\text { ice-more permafrost } \\
\text { ice-rich permafrost }\end{array}$ \\
\hline Thick ice & An earthen or pure sheet of ice over $25 \mathrm{~mm}$ thick & $\begin{array}{l}\text { Including soil ice } \\
\text { ice layer }\end{array}$ & $\begin{array}{l}\text { Including soil ice } \\
\text { ice layer }\end{array}$ \\
\hline
\end{tabular}

Table 2. Soil layer types of the site.

\begin{tabular}{lllll}
\hline Number & Name & try of permafrost & Thickness (m) & Surface depth (m) \\
\hline 1 & cumulosol & Including soil ice & 2.1 & 2.1 \\
2 & ice layer & ice layer & 1.3 & 3.4 \\
3 & cumulosol & Including soil ice & 1.6 & 1.3 \\
4 & silty clay & Including soil ice & 2.4 & 6.0 \\
5 & round gravel & ice-rich permafrost & 2.8 & 8.7 \\
6 & highly weathered tuff & ice-more permafrost & & 11.5 \\
\hline
\end{tabular}

\subsection{Base Pile Temperature Field}

The $28 \mathrm{~d}$ temperature field of foundation pile concrete reflects its curing condition and directly affects its quality. In order to study the temperature field of foundation pile, the temperature changes of pile center and pile wall over time were plotted based on the measured data, See Figures 4 and 5.

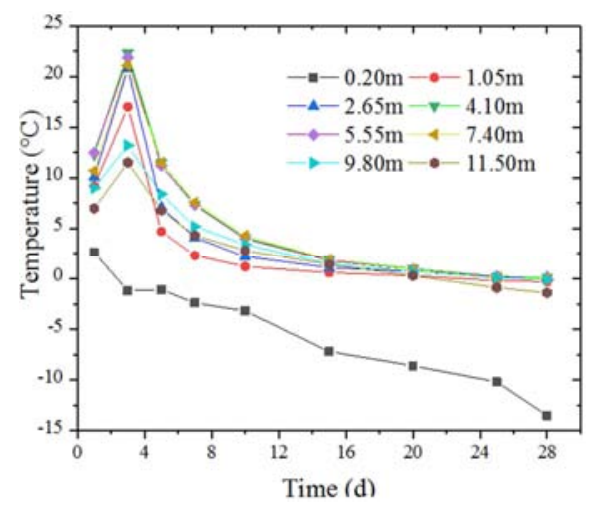

Figure 4. Pile center.

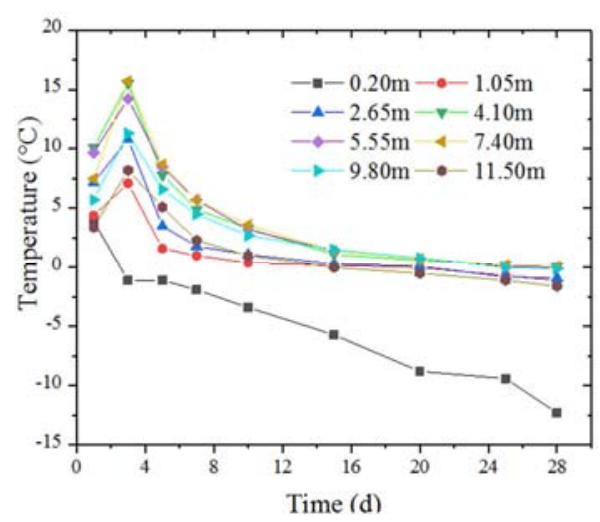

Figure 5. Pile wall.

As can be seen from Figure 4, the temperature of foundation pile at depth of $0.2 \mathrm{~m}$ is significantly lower than that at other depths. Because the place was close to the outside environment, most of the heat generated by the hydration of pile foundation flows into the low-temperature atmosphere. In November 2017, the average temperature was $-24^{\circ} \mathrm{C}$ [19], which led to the temperature at the pile top dropping below $0^{\circ} \mathrm{C}$ at $3 \mathrm{~d}$. Then, the temperature dropped rapidly, and it dropped to $-13.5^{\circ} \mathrm{C}$ at $28 \mathrm{~d}$.

The temperature field below the pile top appears obvious stratification. The highest temperature was $2.65 \mathrm{~m} \sim 7.4 \mathrm{~m}$ in the middle of the pile. The temperature of the lower part decreases as the depth deepens. The temperature in the middle of the pile rose rapidly from 0 to $3 \mathrm{~d}$, and reached the extreme value of $22.3^{\circ} \mathrm{C}$ at $3 \mathrm{~d}$, then the temperature began to gradually decline, and dropped to about $0^{\circ} \mathrm{C}$ at $28 \mathrm{~d}$. The cooling rate at the bottom of the pile was faster than that at the middle, and it was around $0^{\circ} \mathrm{C}$ at $20 \mathrm{~d}$.

By comparing Figure 4 and Figure 5, it can be found that pile center and pile wall have similar variation trend, but there was a temperature difference. The maximum temperature difference appeared on $3 \mathrm{~d}$ after pouring, reaching $6.8^{\circ} \mathrm{C}$, and then gradually decreased. At $28 \mathrm{~d}$, the temperature difference basically disappeared.

\subsection{Permafrost Temperature Field Around the Pile}

The hydration heat of concrete is inevitably transferred to the permafrost, which contains a large amount of ice. The thermal conductivity of ice is obviously greater than that of water, so the permafrost is greatly disturbed. Therefore, in order to study the disturbance radius of concrete hydration heat to permafrost around the pile, the temperature changes of $0.5 \mathrm{~m}$ and $1.5 \mathrm{~m}$ at the pile side are shown in Figures 5 and 6 , respectively.

As can be seen from Figures 6 and 7, the maximum temperature of permafrost does not exceed $0^{\circ} \mathrm{C}$. This was because the latent heat of ice phase transition will absorb a large amount of heat, but the temperature itself will rise slowly, resulting in a small temperature rise of permafrost. The permafrost of $0.5 \mathrm{~m}$ on the side of the pile was significantly 
affected by hydration heat. The extreme temperature in the permafrost occurs at $-0.3^{\circ} \mathrm{C}$ from 5 to 7 days, after which the temperature begins to decline. The temperature at 28 days ranges from $-0.9^{\circ} \mathrm{C}$ to $-1.3^{\circ} \mathrm{C}$, and does not return to the initial ground temperature. Permafrost $1.5 \mathrm{~m}$ away from the pile side was less affected by hydration heat. Except for soil $0.2 \mathrm{~m}$ deep which was significantly affected by external air temperature, the temperature of other soil layers rises at about $0.3^{\circ} \mathrm{C}$ and decreases to $-1.8^{\circ} \mathrm{C}$ at $28 \mathrm{~d}$, which was close to the original ground temperature, indicating that soil $1.5 \mathrm{~m}$ away from the pile side was almost not affected by hydration heat. Therefore, the disturbance radius of foundation pile to permafrost was about $1.5 \mathrm{~m}$.

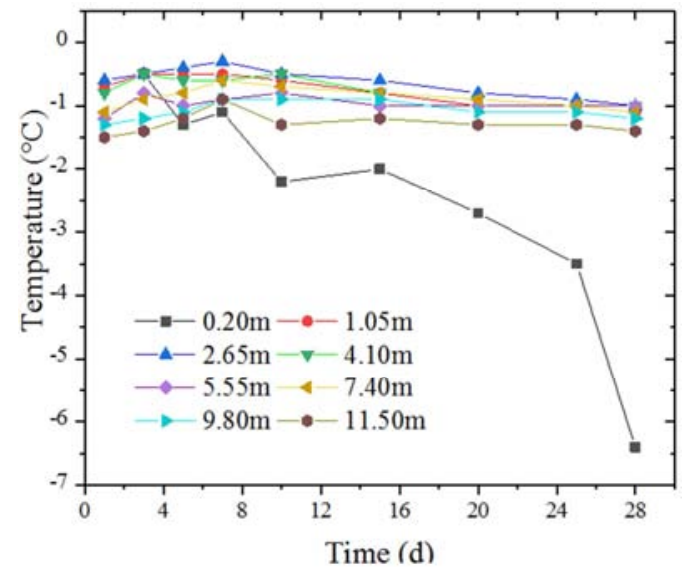

Figure 6. Pile side $0.5 \mathrm{~m}$.

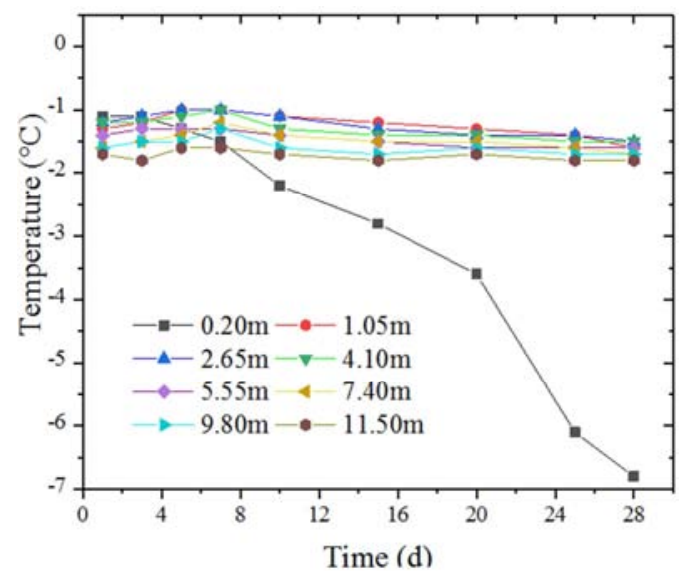

Figure 7. Pile side $1.5 \mathrm{~m}$

\section{Research on the Heat Flow of Foundation Piles}

In the analysis of temperature field, it can be seen that the temperature distribution of permafrost around the pile is very uneven, and there is obvious stratification, to study the causes of this phenomenon. The heat flow of concrete in foundation piles is analyzed below. According to the basic law of heat conduction, heat flow refers to the heat flow per unit area in unit time, which can be calculated by the following formula [20].

$$
\mathrm{q}=\lambda \frac{\left(\theta_{2}-\theta_{1}\right)}{\delta}
$$

Type: $\mathrm{q}$ is the heat flux $\left(\mathrm{w} / \mathrm{m}^{2}\right), \lambda$ is the thermal conductivity $(\mathrm{w} / \mathrm{m} \cdot \mathrm{k}), \theta_{2}$ is the bottom temperature, $\theta_{1}$ is the top temperature, and $\delta$ is the calculated thickness.

\subsection{Pile-Soil Vertical Heat Flow}

Vertical heat flow refers to the transfer of hydration heat along the depth of foundation pile. The pile wall is the main heat loss channel, so the vertical heat flow study mainly analyzes the pile wall. According to Equation (1), the thermal conductivity of concrete is $1.28 \mathrm{w} / \mathrm{m} \cdot \mathrm{k}$, and the temperature gradient is shown in the above temperature field analysis.

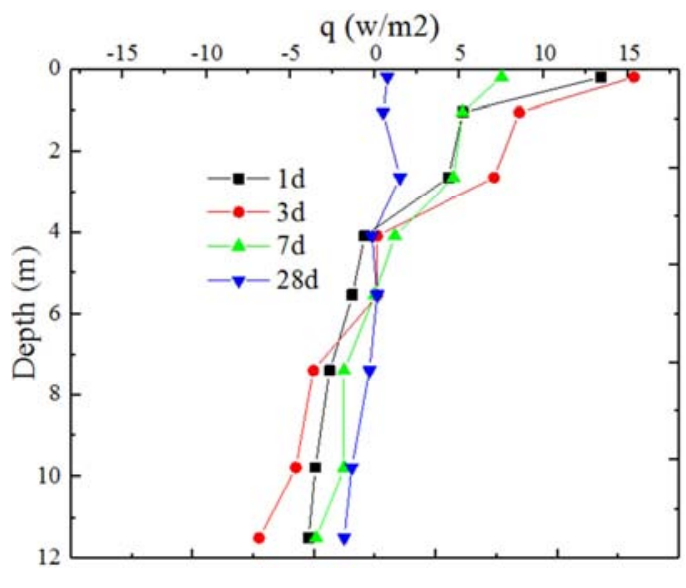

Figure 8. Vertical heat flow distribution.

Figure 8 shows the vertical heat flow distribution at each age after concrete casting. Positive means heat is going up, negative means opposite. On 1d, obvious positive heat flow appears at the top of pile foundation, but not obvious negative heat flow at the bottom. At $3 \mathrm{~d}$, the positive and negative heat flows reached the maximum, and then gradually decreased. At $28 \mathrm{~d}$, the positive and negative heat flows converged to $\pm 2 \mathrm{w} / \mathrm{m}^{2}$.

On the whole, opposite exothermic phenomena occur at pile top and bottom, because heat can be transferred spontaneously from high temperature to low temperature. The pile top at $0.2 \mathrm{~m}$ is affected by external low temperature, and the extreme value of forward heat flow is $15.36 \mathrm{w} / \mathrm{m} 2$ in $3 \mathrm{~d}$. In the pile top temperature field, the temperature has already dropped below $0^{\circ} \mathrm{C}$, which affects the concrete quality of the pile top. Therefore, construction in rich permafrost areas is best in summer. The contact area between the pile bottom and permafrost is relatively large, and the heat of pile foundation can flow into the permafrost rapidly. In $3 \mathrm{~d}$, the negative heat flow reaches an extreme value of $-6.84 \mathrm{w} / \mathrm{m}^{2}$, resulting in a rapid drop in the temperature of the pile bottom.

With the deepening of depth, the heat flow of foundation pile $0.2-4.1 \mathrm{~m}$ gradually decreases. The vertical heat flow at a depth of $4.1 \mathrm{~m} \sim 7.4 \mathrm{~m}$ is basically maintained at about $0 \mathrm{w} / \mathrm{m}^{2}$, indicating that the heat flow here neither transfers upward nor transfers downward. As can be seen in section 3-1 above, the temperature here is the highest. This phenomenon is analyzed 
below.

\subsection{Horizontal Pile-Soil Heat Flow}

Horizontal heat flow refers to the transfer between concrete hydration heat and permafrost around the pile. The thermal conductivity of frozen soil needs to be measured when calculating heat flow q according to Equation (1). The thermal conductivity of permafrost is slightly increased with the decrease of negative temperature, but the increase is very small. In general thermal calculation, the thermal conductivity can only be taken in freeze-thaw state and ignore the influence of temperature [20]. Therefore, the thermal conductivity of permafrost under freezing-thawing condition has been measured in laboratory. The test instruments and data are shown in Figure 9 and Table 3 The perturbed radius of permafrost around the pile is about $1.5 \mathrm{~m}$. When calculating the lateral heat flow $\mathrm{Q}$, the soil within the width range of $1.5 \mathrm{~m}$ on the side of the pile is calculated.

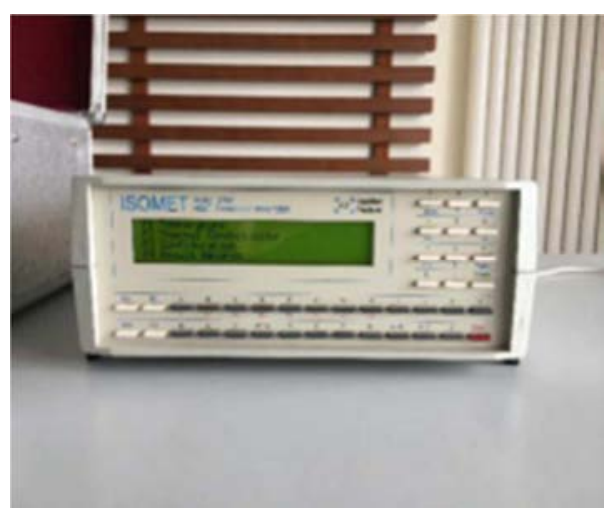

Figure 9. ISOMET2104 heat transfer analyzer.

Table 3. Thermal conductivity of soil.

\begin{tabular}{lllll}
\hline \multirow{2}{*}{ Number } & Name & \multirow{2}{*}{ Depth $(\mathbf{m})$} & \multicolumn{2}{c}{ Thermal conductivity $(\mathbf{w} / \mathbf{m} \cdot \mathbf{k})$} \\
\cline { 3 - 5 } 1 & Freeze & 1.01 & Thaw \\
2 & cumulosol & 0.2 & 2.21 & 0.60 \\
3 & ice layer & 1.05 & 1.01 & 0.58 \\
4 & cumulosol & 4.65 & 2.09 & 1.72 \\
5 & silty clay & 5.55 & 1.78 & 1.77 \\
6 & round gravel & 7.4 & 1.03 & 0.79 \\
\hline
\end{tabular}

In Figure 10, the positive value represents the concrete hydration heat flow to permafrost, and vice versa. It can be seen from the figure below that only $0.2 \mathrm{~m}$ depth of soil layer presents negative heat flow, while the remaining depths are all positive heat flow. It shows that the lateral heat flow direction of the pile is mainly from the foundation pile to the permafrost in $28 \mathrm{~d}$.

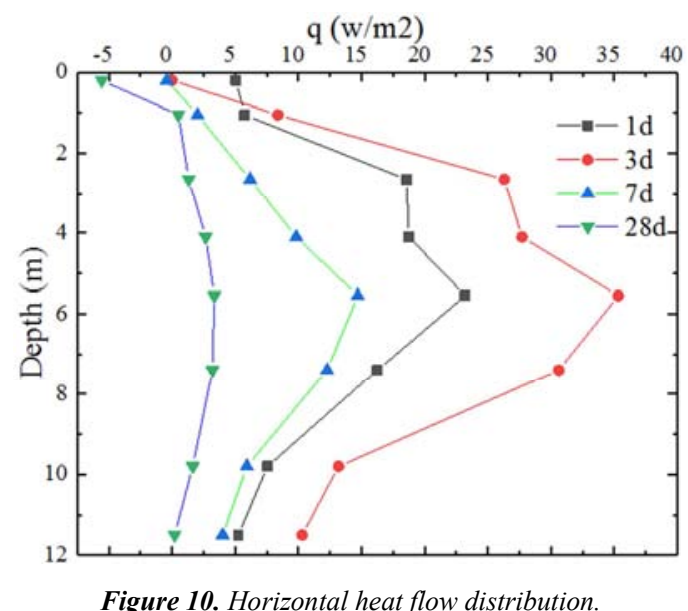

The value of the horizontal heat flow is $2 \sim 3$ times that of the vertical heat flow. Its distribution is in descending order: the middle, the top and the bottom of the pile. This is due to the different thermal conductivity between the soil layers. The thermal conductivity is the largest at $2.65 \mathrm{~m}$ ice layer, and the transverse heat flow is indeed small. The reason is that part of the heat of the pile foundation at $2.65 \mathrm{~m}$ depth is lost from the pile top, leading to the relative decrease of the transverse heat flow.

The rate of transverse heat flow between pile and soil increases due to high ice content and high thermal conductivity in the middle of the pile. In $3 \mathrm{~d}$, the heat flow reaches a maximum of $35.32 \mathrm{w} / \mathrm{m} 2$. Make pile center and pile wall form big temperature difference. Local high temperature zone is formed inside the pile due to the relatively slow absorption process of thawing permafrost. Then the temperature dropped rapidly, reaching $0^{\circ} \mathrm{C}$ at $28 \mathrm{~d}$. That is, the foundation pile and surrounding permafrost began to refreeze.

The rapid lateral heat flow not only affects the temperature field of the pile, but also increases the thermal disturbance to the permafrost around the pile. Insulation layer can be added to the outside of the foundation pile during construction to obtain more uniform concrete temperature field, so as to improve the concrete strength and reduce the disturbance to the permafrost.

\section{Conclusion}

1) Vertical heat flow mainly appears on the top of foundation pile, and reaches the extreme value of $15.36 \mathrm{w}$ $/ \mathrm{m} 2$ in $3 \mathrm{~d}$, leading to a rapid decline in the top temperature, which drops below $0^{\circ} \mathrm{C}$ in $3 \mathrm{~d}$. It is difficult to guarantee the concrete quality of pile top.

2) The value of the horizontal heat flow is $2 \sim 3$ times that of the vertical heat flow, it is the main way of heat loss of pile concrete. 
3) The rate of horizontal heat flow between pile and soil increases due to high ice content and high thermal conductivity. Make pile center and pile wall form big temperature difference. Local high temperature zone is formed inside the pile due to the relatively slow absorption process of thawing permafrost. Then the temperature dropped rapidly, reaching $0^{\circ} \mathrm{C}$ at $28 \mathrm{~d}$. It also increases the perturbed range of permafrost around the pile.

\section{References}

[1] Guo Jing-Ting, Han Feng-Lin, Hu Yuan-Man, et al. Ecological characteristics of vegetation and their responses to permafrost degradation in the north slope of Great Khingan Mountain valley of northeast China [M]. Acta Ecologica Sinica, 2017, 37 (19): 6552-6561.

[2] LENG Yi-fei, ZHANG Xi-Fa, YANG Feng-Xue, et al. Experimental research on unfrozen water content of frozen soils by calorimetry [J]. Rock and Soil Mechanics, 2010: 3759.

[3] LIU Shi-Wei, ZHANG Ming-Jian. Research status of physical and mechanical properties of high temperature frozen soil [J]. Journal of Glaciology and Geocryology, 2012, 34 (01): 121.

[4] SHANG Yun-Hu, NIU Fu-Jun, LIU Ming-Haoet al. Long-term effect of a pile foundation on ground temperatures in permafrost regions $[\mathrm{J}]$. Chinese Journal of Rock Mechanics and Engineering, 2017, 36 (09): 2313-2323.

[5] XU Chu-Hua. Research on axial bearing behavior of cast-in-place concrete pile in permafrost region [D]. Harbin: Harbin Institute of Technology, 2009, 1.

[6] WANG Xiao-Li, CHEN Pin-Zhi, WU Shao-Hai. Research and application of the form of Qinghai-Tibet Railway Foundation pile [J]. Chinese Railways, 2003, (1): 66-68.

[7] FU Jin, JIANG Yu, PENG Hui, et al. Early refreezing law of large-diameter cast-i-place piles in permafrost regions [J]. Journal of Traffic and Transportation Engineering, 2016, 16 (4): 121.

[8] XION Wei, LIU Ming-Gui, ZHANG Qi-Heng, et al. Study on the temperature field of foundation piles in permafrost regions [J]. Rock and Soil Mechanics, 2009, 30 (6): 1658-1664.

[9] SHANG Yun-Hu, YUAN Kun, NIU Fu-Jun, et al. Study on ground temperature of cast-in-place pile of bridge in permafrost regions [J]. Journal of Glaciology and Geocryology, 2016, 38 (4): 1129-1135.
[10] WANG Xu, JIANG Dai-jun, ZHAO Xin-yu, et al. An experimental study on refreezing characteristics of large-diameter bored pile in different permafrost areas of the Qinghai-Tibet plateau [J]. Chinese Journal of Rock Mechanics and Engineering, 2004, 23 (24): 4206-4211.

[11] WANG Xu, JIANG Daijun, ZHAO Xinyu, et al. Experimental study on bearing features of bored pile under non-refreezing condition in permafrost region $[\mathrm{J}]$. Chinese Journal of Geotechnical Engineering, 2005, 27 (1): 81-84.

[12] WANG Xu, JIANG Daijun, LIU Deren, et al. Experimental study of bearing characteristics of large-diameter cast in-place bored pile under non-refreezing condition in low-temperature permafrost ground $[\mathrm{J}]$. Chinese Journal of Rock Mechanics and Engineering, 2013, 32 (9): 1807-1 812.

[13] CHAO Dong-Gen, LI Jing-Ping. Experimental Analysis on the Thermal Influence of Cast-in-place Pile's Casting Temperature and Hydration Heat on its Surrounding Frozen Soil [J]. Highway, 2017, 6 (3): 55-58.

[14] Lei Shen, Qingwen Ren, Gianluca Cusatis, et al. Numerical Study on Crack Thermal Resistance Effect on Thermo-Mechanical Coupled Behavior of Concrete Structure at Room Temperature [J]. International Journal of Solids and Structures, 2020, 6 (4): 182-183.

[15] Orlando B, Andersland, Branko Ladanyi. Frozen Ground Engineering, and Edition [M]. Beijing: China Architecture \& Building Press. 2011. 7: 47.

[16] Yuan Xizhong, Ma Wei, Liu Yongzhi. Study on thermal regime of high-temperature frozen soil while construction of cast-in-place pile [J]. Chinese Journal of Rock Mechanics and Engineering, 2005 (6): 1052-1055.

[17] ZHENG Xian-Chang, ZHENG Wei-Feng. Simulation test and basic Countermeasure research on thawing subsidence and frost heave of frozen soil in Zhongshan Station, Antarctica, China [J]. Industrial architecture. 2010, 6 (27): 155.

[18] Ministry of Construction, PRC. GB50324-2014Code for permafrost Engineering Geological survey [S]. State Forestry Bureau, 2014.

[19] China Meteorological Data Network. https://data.cma.cn/data/cdcindex/cid/6d1b5efbdcbf9a58.html ?pid=3372324af43a4fef. National Meteorological Science Data Center.

[20] XU Xue-Zu, WANG Jia-Cheng, ZHAN Li-xin. Permafrost physics [M]. Beijing: Science Press, 010: 79-106. 